

\title{
Enzyme immunoassay for a urinary metabolite of 4-hydroxynonenal as a marker of lipid peroxidation
}

Françoise Guéraud, Géraldine Peiro, Herve H. Bernard, Jacques Alary, Christophe Créminon, Laurent Debrauwer, Estelle Rathahao, Marie-Francoise Drumare, Cécile Canlet, Jean-Michel J.-M. Wal, et al.

\section{To cite this version:}

Françoise Guéraud, Géraldine Peiro, Herve H. Bernard, Jacques Alary, Christophe Créminon, et al.. Enzyme immunoassay for a urinary metabolite of 4-hydroxynonenal as a marker of lipid peroxidation. Free Radical Biology and Medicine, 2006, 40 (1), pp.54-62. 10.1016/j.freeradbiomed.2005.08.011. hal-02662857

\section{HAL Id: hal-02662857 https://hal.inrae.fr/hal-02662857}

Submitted on 31 May 2020

HAL is a multi-disciplinary open access archive for the deposit and dissemination of scientific research documents, whether they are published or not. The documents may come from teaching and research institutions in France or abroad, or from public or private research centers.
L'archive ouverte pluridisciplinaire HAL, est destinée au dépôt et à la diffusion de documents scientifiques de niveau recherche, publiés ou non, émanant des établissements d'enseignement et de recherche français ou étrangers, des laboratoires publics ou privés. 


\title{
Enzyme immunoassay for a urinary metabolite of 4-hydroxynonenal as a marker of lipid peroxidation
}

\author{
Françoise Guéraud ${ }^{\mathrm{a}, *}$, Géraldine Peiro ${ }^{\mathrm{a}}$, Hervé Bernard ${ }^{\mathrm{c}}$, Jacques Alary ${ }^{\mathrm{a}}$, Christophe Créminon ${ }^{\mathrm{b}}$, \\ Laurent Debrauwer ${ }^{\mathrm{a}}$, Estelle Rathahao ${ }^{\mathrm{a}}$, Marie-Françoise Drumare ${ }^{\mathrm{c}}$, Cécile Canlet ${ }^{\mathrm{a}}$, \\ Jean-Michel Wal ${ }^{c}$, Georges Bories ${ }^{\text {a }}$ \\ ${ }^{a}$ Institut National de la Recherche Agronomique, UMR-1089 Xénobiotiques, INRA/ENVT, BP 3, 180 chemin de Tournefeuille, 31931 Toulouse Cedex 9, France \\ ${ }^{\mathrm{b}}$ Service de Pharmacologie et d'Immunologie, CEA-Saclay, Gif-sur-Yvette, France \\ c INRA-Laboratoire d'Immuno-allergie Alimentaire, SPI, CEA-Saclay, Gif-sur-Yvette, France
}

Received 24 May 2005; revised 11 July 2005; accepted 9 August 2005

Available online 2 September 2005

\begin{abstract}
Free radical reactions are involved in the pathogenesis of numerous diseases, so there is a real need to develop biomarkers that reflect these reactions in vivo. 4-Hydroxy-2-nonenal (HNE) is a major product of the lipid peroxidation process that is a consequence of free radical reactions. We present here the development and validation of an enzyme immunoassay (EIA) of the major urinary metabolite of HNE, namely 1,4dihydroxynonane-mercapturic acid (DHN-MA). EIA allowed direct measurement of DHN-MA in rat urine with good sensitivity (0.02 ng/ml) and precision (intraassay $\mathrm{CV}=5.7 \%$ ). Recovery was complete $(99-102 \%)$. Cross-reactivity was very low with 1,4-dihydroxynonene and with different mercapturic acids except with one other HNE urinary metabolite. Good correlation $\left(\mathrm{EIA}=0.79 \times \mathrm{LC} / \mathrm{MS}+14.03, r=0.877, P<10^{-8}\right.$ ) was obtained between EIA and liquid chromatography/mass spectrometry (LC/MS) quantitation when analyzing urine samples of rats with different oxidative status, due to treatment with either $\mathrm{BrCCl}_{3}$ or trinitrobenzene sulfonic acid, which are known to induce hepatic lipid peroxidation or colon inflammation, respectively.
\end{abstract}

(C) 2005 Elsevier Inc. All rights reserved.

Keywords: 1,4-Dihydroxynonane-mercapturic acid; HNE; EIA; Lipid peroxidation; Biomarkers; Oxidative stress; Free radicals

\section{Introduction}

Cardiovascular diseases such as atherosclerosis or cerebral or heart ischemia-reperfusion injury, neurodegenerative diseases, diabetes, inflammation, and cancer are major health

Abbreviations: AChE, acetylcholinesterase; AGC, automatic gain control; BHT, butylated hydroxytoluene; BSA, bovine serum albumin; CRM, consecutive reaction monitoring; DCC, dicyclohexylcarbodiimide; DHN, 1,4-dihydroxy-2-nonene; DHN-MA, 1,4-dihydroxynonane-mercapturic acid; DMF, dimethylformamide; EIA, enzyme immunoassay; FIDs, free induction decays; HNA, 4-hydroxy-2-nonenoic acid; HNE, 4-hydroxy-2-nonenal; HPLC, highperformance liquid chromatography; LC/MS, liquid chromatography/mass spectrometry; LC-MS-MS, liquid chromatography/tandem mass spectrometry; MA, mercapturic acid ( $\mathrm{N}$-acetylcysteine); MDA, malondialdehyde; NHS, $\mathrm{N}$ hydroxysuccinimide; NMR, nuclear magnetic resonance; ROS, reactive oxygen species; TLC, thin layer chromatography.

* Corresponding author. Fax: +33 561285244.

E-mail address: fgueraud@toulouse.inra.fr (F. Guéraud). problems in industrialized countries. A common feature of these diseases is the involvement of free radical reactions in their pathogenesis [1]. It is thus of great importance to be able to monitor the involvement of these reactions during the pathogenesis of these diseases. In addition, measurements of these reactions could provide useful tools for diagnosis or prognosis purposes. However, reactive oxygen species (ROS) are extremely reactive compounds with an ultra short half-life, which is a serious drawback for their measurement. Free radical attacks on polyunsaturated fatty acids during the lipid peroxidation process lead to the formation of several downstream compounds that are much more stable than ROS.

Two kinds of compounds could be used as biomarkers of oxidative damage. The first are prostaglandin $\mathrm{F}_{2}$-like compounds that are formed nonenzymatically in vivo by free radical-induced peroxidation of arachidonic acid. One $\mathrm{F}_{2}$ isoprostane, namely 8 -epiPGF $2 \alpha$, has been used as a lipid peroxidation biomarker for the last few years [2]. The second 
kind of compound is $\beta$-cleavage products of oxidized polyunsaturated fatty acids, such as alkanes, ketones, or aldehydes. Exhaled alkanes have been used as biomarkers of lipid peroxidation but, due to methodological difficulties, these compounds are not convenient for routine testing [3]. Two well-known aldehydes formed during the lipid peroxidation process, namely malondialdehyde (MDA) and 4-hydroxy-2nonenal (HNE) [4], have already been used as lipid peroxidation biomarkers for decades [5,6]. Moreover, HNE is not merely a product of lipid peroxidation, but has also been shown to be a growth-regulating factor, and, more recently, to play a role in intracellular signal transduction. This biological role is due to the chemical reactivity of HNE and its ability to make covalent links with proteins and to modify their function [7-10]. This is why HNE or its metabolites would be good candidates for lipid peroxidation biomarkers. Measurement of protein/HNE adducts in tissues, using polyclonal or monoclonal antibodies for their detection by immunoblotting or immunohistochemistry, makes HNE even more attractive in the field of clinical and experimental studies $[6,11,12]$. However, as neither HNE nor protein/HNE adducts are present in urine, we wanted to validate HNE urinary end-products as noninvasive biomarkers of lipid peroxidation and oxidative stress. This could be useful as a complement or as a screening method for HNE/protein immunodetection.

In a previous work, we showed that 1,4-dihydroxynonanemercapturic acid (DHN-MA), the major urinary metabolite of HNE in rat, was present at a physiological level in rat and human urine [13]. Very recently, we showed that DHN-MA increased in the urine of rats treated with $\mathrm{BrCCl}_{3}$, which induces lipid peroxidation, at the same magnitude as MDA and 8 -epiPGF ${ }_{2 \alpha}$, which were measured concomitantly [14]. However, the LC-MS methodology used to quantify this compound in our previous studies is too sophisticated and too timeconsuming to be used for routine testing in clinical studies or for health monitoring.

The aim of the current study was to develop and validate an enzyme immunoassay (EIA) for DHN-MA measurement in urine using polyclonal antibodies. To our knowledge, this is the first enzyme immunoassay available measuring HNE metabolites. Validation was achieved using rat urine samples corresponding to different oxidative status, by comparing measurements by LC/MS and by the new EIA.

\section{Materials and methods}

\section{Chemicals}

Butylated hydroxytoluene (BHT), $N$-hydroxysuccinimide (NHS), dicyclohexylcarbodiimide (DCC), bromotrichloromethane $\left(\mathrm{BrCCl}_{3}\right)$, bovine serum albumin (BSA), sodium borohydride, $N$-acetyl-L-cysteine, trans-crotonaldehyde, trans-2-hexene, trans-2-nonene, 3-methylindole were purchased from Sigma-Aldrich Chimie (Saint-Quentin-Fallavier, France). HNE diethylacetal was synthesized as described by Esterbauer and Weger [15]. Just before use, the diethylacetal derivative was hydrolyzed with $1 \mathrm{mM} \mathrm{HCl}$ for $1 \mathrm{~h}$ at room temperature. The aqueous solution was vortex-extracted five times with dichloromethane. The organic phase containing HNE was filtered on a phase-separation filter (Whatman SP1, Maidstone, UK) and evaporated under vacuum without heating. The liquid residue was resolubilized in distilled water and the HNE concentration was determined spectrophotometrically at $223 \mathrm{~nm}$. HNE was used for the preparation of DHNMA and some different reference compounds for crossreactivity studies. $\left[{ }^{3} \mathrm{H}\right] \mathrm{DHN}-\mathrm{MA}$ (specific activity: $180 \mathrm{GBq} /$ mmol) was synthesized from $\left[4-^{3} \mathrm{H}\right] \mathrm{HNE}$ as previously described [13]. $\left[4-{ }^{3} \mathrm{H}\right] \mathrm{HNE}$ diethylacetal was synthesized at CEA, Service des Molécules Marquées CEN (Saclay, France), according to a method developed in the laboratory [16].

4-Hydroxyoctenal and 4-hydroxyundecenal standards were kindly provided by Dr. Daniella Zanetti from Turin University, Italy. 4-Hydroxyhexenal was a generous gift from Prof. Hank Segall, Davis, California.

All chemicals, solvents, and reagents for the preparation of buffers and HPLC eluents were of the highest grade commercially available from Merck (Nogent-sur-Marne, France). Ultrapure water from Milli-Q system (Millipore, Saint-Quentin-en-Yvelines, France) was used for HPLC eluent preparation.

\section{Urine collection}

Urine was collected daily from rats housed in plastic metabolic cages. One milliliter of a $360 \mathrm{mM}$ BHT ethanolic solution was added to the urine collection tubes that were placed in a unit maintained at $0^{\circ} \mathrm{C}$ during urine collection. Urine volumes were determined and then adjusted to $20 \mathrm{ml}$ with distilled water. The 24-h urine samples were stored at $-80^{\circ} \mathrm{C}$ until further analysis.

Seventy-day-old male Wistar rats $(230-250$ g) were purchased from Harlan (Granat, France) and fed ad libitum a semipurified diet (AIN 76 or UAR 210, from UAR, Epinay, France).

Some of the animals were given by gastric intubation a single dose $(0.1 \mathrm{ml} / \mathrm{kg} / \mathrm{BW})$ of $\mathrm{BrCCl}_{3}$, which is a chemical inducer of lipid peroxidation, with paraffin oil $(1 / 9, \mathrm{v} / \mathrm{v})$ used as vehicle. Control rats received an equal volume of paraffin oil. Urine was collected 2 days before and 5 days after the treatment.

Some of the animals received by intracolonic instillation 40 $\mathrm{mg} / \mathrm{kg} / \mathrm{BW}$ of trinitrobenzene sulfonic acid $(0.5 \mathrm{M})$ in ethanol/ water $(50 / 50, \mathrm{v} / \mathrm{v})$, which is an inducer of colon inflammation, brought to a $100-\mu$ l final volume with $0.9 \% \mathrm{NaCl}$, while controls received only saline solution.

Experiments were performed according to institutional guidelines governing animal experimentation.

\section{Preparation of polyclonal antiserum}

\section{Synthesis of DHN-MA}

DHN-MA was synthesized from HNE as previously described [13]. Briefly, HNE was reacted with a stoichiometric amount of $\mathrm{N}$-acetyl-L-cysteine for $24 \mathrm{~h}$ at $37^{\circ} \mathrm{C}$. The resulting 
HNE-MA was reduced by sodium borohydride. DHN-MA was then purified by semipreparative HPLC. The product was analyzed by proton NMR as described in the same study [13].

\section{Activated ester synthesis from DHN-MA}

DHN-MA was covalently coupled to the immunogenic carrier or to enzymatic tracer via its carboxylic group. Briefly, $10 \mu \mathrm{mol}$ of DHN-MA (3.2 mg) in methanol was dried under a nitrogen stream. After solubilization of the residue in $500 \mu \mathrm{l}$ of dimethylformamide (DMF), $11 \mu \mathrm{mol}$ of NHS $(1.25 \mathrm{mg}$ in 250 $\mu \mathrm{l}$ of DMF) and $10 \mu \mathrm{mol}$ of DCC (2.66 mg in $250 \mu \mathrm{l}$ of DMF) were added successively. The reaction mixture was stirred for $18 \mathrm{~h}$ at room temperature under darkness.

\section{Immunogen preparation}

Twenty milligrams of keyhole limpet hemocyanin (Merck, Nogent-sur-Marne, France) solubilized in $5.8 \mathrm{ml} 0.1 \mathrm{M}$ borate buffer (pH 9.0) was added in a volume of $850 \mu$ containing 8.5 $\mu \mathrm{mol}$ of activated ester prepared from DHN-MA. After $6 \mathrm{~h}$ of stirring at room temperature, the immunogenic mixture was divided into $1.1-\mathrm{ml}$ aliquots ( $3 \mathrm{mg}$ of protein) and stored at $-20^{\circ} \mathrm{C}$ until use.

\section{Immunization}

Anti-DHN-MA antisera were obtained by immunizing white "Blanc-de-Bouscat" adult male rabbits as follows: $1.5 \mathrm{ml}$ of diluted immunogen $(400 \mu \mathrm{l}$ of water added to $1.1 \mathrm{ml}$ of aliquots of mixture) was emulsified with $1.5 \mathrm{ml}$ of Freund's complete adjuvant (Difco, Detroit, MI) and injected subcutaneously into three rabbits. Booster injections were given 6 weeks later and every month thereafter. Rabbits were bled 10 days after each immunization. Sera were stored at $4^{\circ} \mathrm{C}$ after addition of sodium azide $(0.01 \%$ final concentration).

\section{Enzymatic tracer synthesis}

Enzymatic tracer was prepared by covalent linkage of DHNMA to the tetrameric form of acetylcholinesterase (AChE; EC 3.1.1.7) as previously described [17]. This method involved the reaction of activated ester from DHN-MA (100 nmol) to AChE $(0.3 \mathrm{nmol})$ solubilized in $990 \mu \mathrm{l}$ of $0.1 \mathrm{M}$ borate buffer. The reaction was allowed to proceed for $18 \mathrm{~h}$ at $4^{\circ} \mathrm{C}$ and the conjugate was then purified using chromatography on a biogel $1.5 \mathrm{M}$ column as previously described [17].

\section{Competitive EIA}

The assay is based on competitive EIA as previously described for eicosanoids $[18,19]$. DHN-MA, which is present in the standard solution or in the urine samples, inhibits binding between anti-DHN-MA polyclonal antibodies and the DHNMA-linked acetylcholinesterase enzyme (tracer).

Briefly, competitive enzyme immunoassays were performed using 96-well microtiter plates coated with mouse monoclonal anti-rabbit IgG $(10 \mu \mathrm{g} / \mathrm{ml}$ in $50 \mathrm{mM}$ phosphate buffer, $\mathrm{pH} 7.4$, for $18 \mathrm{~h}$ at $4^{\circ} \mathrm{C}$ before saturating with EIA buffer corresponding to $0.1 \mathrm{M}$ potassium phosphate, $\mathrm{pH} 7.4$, containing $0.15 \mathrm{M}$
$\mathrm{NaCl}, 0.1 \% \mathrm{BSA}$, and $0.01 \%$ sodium azide), in order to ensure separation of bound and free fractions of the enzymatic tracer during the immunological reaction. The total volume of the immunological reaction was $150 \mu \mathrm{l}$, each component (enzymatic tracer, rabbit polyclonal antisera, and standard or sample diluted in EIA buffer) being added in a $50-\mu 1$ volume. The enzymatic tracer was used at a concentration of 2 Ellman units/ $\mathrm{ml}$ [20] while the working dilutions for the corresponding rabbit antisera were previously determined by performing serial dilution experiments. A calibration curve was performed with a standard solution (16 pg/ml-10 ng/ml of DHN-MA). The urine samples were assayed without any purification step in duplicate with four dilutions $(1 / 20$ to $1 / 200)$.

After $18 \mathrm{~h}$ of incubation at $4^{\circ} \mathrm{C}$, the plates were washed (with $10 \mathrm{mM}$ phosphate buffer, $\mathrm{pH} 7.4$, containing $0.05 \%$ Tween 20) before the enzyme activity of the bound immunological complex was quantified by the addition of $200 \mu \mathrm{l} / \mathrm{well}$ of Ellman's reagent (mix of $0.75 \mathrm{mM}$ substrate, acetylthiocholine iodide, and $0.5 \mathrm{mM}$ chromogen, 5,5'-dithiobis(2-nitrobenzoic acid)). After 1 or $2 \mathrm{~h}$ of gentle shaking in the dark at room temperature, the absorbance at $414 \mathrm{~nm}$ of each well was measured using an automatic plate reader. Results were expressed in terms of $B / B_{0} \%$ as a function of the dose (logarithmic scale), $B$ and $B_{0}$ representing the bound activity in the presence or absence of competitor, respectively. All measurements for standards and samples were made in duplicate, and in quadruplicate for $B_{0}$ values. A linear loglogit transformation was used to fit the standard curve. The assay sensitivity was characterized by the dose of standard that induced a $50 \%$ inhibition of the binding observed in the absence of competitor $\left(50 \% \mathrm{~B} / \mathrm{B}_{0}\right)$. The minimum detectable concentration corresponded to an $80 \%$ inhibition of the binding $\left(80 \% B / B_{0}\right)$.

The specificity of the EIA was checked by testing its capacity to detect compounds structurally related to DHN-MA by establishing the corresponding standard curves for each. Results were expressed as the percentage of cross-reactivity (CR), defined as the ratio (\%) of the concentration of DHN$\mathrm{MA}$ and related compounds at $50 \% B / B_{0}$ [21]. All results related to DHN-MA assay in urine $(\mathrm{ng} / \mathrm{ml})$ were expressed on the basis of a 24-h excretion.

\section{Syntheses of standards for cross-reactivity studies}

1,4-Dihydroxy-2-nonene (DHN) and 4-hydroxy-2-nonenoic acid (HNA) were synthesized as previously described [22]. The mercapturic derivatives of HNE (HNE-MA), 4-hydroxynonenoic acid (HNA-MA), and its lactone derivative (HNA-lactMA) were synthesized from HNE as previously described [22]. Mercapturic derivatives of 2-hexenal, 2-nonenal, crotonaldehyde, 4-hydroxyhexenal, 4-hydroxyoctenal, 4-hydroxyundecenal, and 3-methylindole were synthesized as previously described for DHN-MA [22] and the subsequent reduction of the aldehyde function, when necessary, was done using sodium borohydride [13].

The mercapturic derivative of 1,3,4-trihydroxynonane was synthesized as follows: (i) Epoxidation and mercapturization of 
HNE were achieved by using 0.1 mmol HNE (with radiolabeled HNE used as tracer) which was reacted with $1 \mathrm{mmol}$ $\mathrm{H}_{2} \mathrm{O}_{2}$ in phosphate buffer $(0.4 \mathrm{M}, \mathrm{pH} 7.4)$ for $20 \mathrm{~h}$ at $37^{\circ} \mathrm{C}$ with stirring [23]. The solution was extracted 5 times with dichloromethane. Pooled dichloromethane phases were filtered on a Whatman SP1 phase-separation filter and concentrated to about $2 \mathrm{ml}$. HNE-epoxide was purified by TLC with a $20 \times$ $20 \times 0.5-\mathrm{mm}$ silica plate developed with dichloromethane/ methanol $(95 / 5, \mathrm{v} / \mathrm{v})$. Radioactive spots were detected with a TLC Linear Analyzer LB 2832 (Berthold France, La GarenneColombes, France). The HNE-epoxide spot (Rf 0.35) was scraped off. The silica was extracted with $50 \mathrm{ml}$ dichloromethane. The dichloromethane was evaporated and the residue was redissolved in phosphate buffer (0.2 M, pH 7.6) and added to a stoichiometric amount of $N$-acetyl-L-cysteine. The solution was maintained at $37^{\circ} \mathrm{C}$ and stirred for $65 \mathrm{~h}$. The reaction mixture was then extracted 4 times by $5 \mathrm{ml}$ dichloromethane. Traces of solvent were removed from the aqueous phase by nitrogen bubbling and the $\mathrm{pH}$ was brought to 2.5 with phosphoric acid. 3,4-Dihydroxynonanal mercapturic acid was purified with a $\mathrm{C} 18$ cartridge as described above. This product was checked by LC-MS-MS. (ii) Reduction of the aldehydic group of 3,4-dihydroxynonanal mercapturic acid was done using sodium borohydride [13].

\section{Synthesis of (4R)- and (4S)-DHN-MA}

$(4 R)$-DHN-MA and (4S)-DHN-MA were synthesized from $(4 R)-\mathrm{HNE}$ and $(4 S)$-HNE, respectively, as previously described. (4R)-HNE and (4S)-HNE were obtained from racemic HNE according to the method of Allevi et al. [24]. (4R)-DHNMA was used as reference compound for EIA analysis (see Results).

\section{DHN-MA purification from urine samples and LC-MS analysis}

DHN-MA was analyzed by LC/MS as previously described with some minor modifications [25].

A $18-\mathrm{ml}$ aliquot of urine previously filtered on glass microfiber filters $(1.2 \mu \mathrm{m}$, Whatman) was spiked with $10 \mu \mathrm{l}$ methanol containing $300 \mathrm{~Bq}\left[{ }^{3} \mathrm{H}\right] \mathrm{DHN}-\mathrm{MA}$ as tracer. The sample was applied to a 1-g LC-C18 cartridge (Supelco, SaintQuentin-Fallavier, France) preconditioned with methanol (10 $\mathrm{ml})$ and distilled water $(10 \mathrm{ml})$. The cartridge was then washed with distilled water $(20 \mathrm{ml})$, dried under a nitrogen stream, and eluted with methanol $(10 \mathrm{ml})$. The eluate was evaporated to dryness under vacuum.

\section{HPLC purification}

The residue was dissolved in $500 \mu$ l eluent A containing ammonium acetate $(20 \mathrm{mM}$ adjusted to $\mathrm{pH} 4.5$ with acetic acid)/acetonitrile $(90: 10, \mathrm{v} / \mathrm{v})$. HPLC purification was performed on a Spherisorb ODS2 column $(5 \mu \mathrm{m}, 250 \times 4.6 \mathrm{~mm})$ from Interchim (Montluçon, France), protected by a Spherisorb precolumn $(5 \mu \mathrm{m}, 10 \times 4.6 \mathrm{~mm})$. Eluent B consisted of water/ acetic acid/acetonitrile (79/1/20, v/v/v). Solvents were delivered at a flow rate of $1 \mathrm{ml} / \mathrm{min}$ as follows: $0-20 \mathrm{~min}, 100 \% \mathrm{~A}$;
20-60 $\mathrm{min}, 100 \% \mathrm{~B}$. The fractions were collected with a Gilson Model 202 fraction collector (Gilson France, Villiers-leBel, France) at a collection rate of 4 fractions per minute. A 25$\mu \mathrm{l}$ aliquot of all the fractions was counted for radioactivity in a Model 4330 Packard Tricarb scintillation counter (PerkinElmer, Les Ulis, France) using Ultimagold (Perkin-Elmer) as scintillation cocktail. The fractions containing radioactivity (retention time from 27.15 to $29.15 \mathrm{~min}$ ) were combined and evaporated to dryness under vacuum.

\section{Preparation of sample solutions for LC-MS analysis}

A deuterated analogue of DHN-MA with six deuterium atoms was used as internal standard for mass spectrometry quantitation of DHN-MA [25].

Each dry urine extract was dissolved in $50 \mu \mathrm{l}$ of a solution containing $1 \mathrm{ng} / \mu \mathrm{l}$ internal standard. The LC/MS analyses were carried out by injecting $20 \mu \mathrm{l}$ of the final solution (20 $\mathrm{ng}$ internal standard injected).

\section{Liquid chromatography-tandem mass spectrometry}

Liquid chromatography was used to introduce the analyte solution into the ion source at a flow rate of $0.2 \mathrm{ml} / \mathrm{min}$ using a Thermo Separation P4000 pump (Thermo Finnigan, Les Ulis, France) fitted with a Rheodyne injector. The LC column was a Kromasil $100 \mathrm{C} 18(5 \mu \mathrm{m}, 250 \times 2 \mathrm{~mm})$ column. The following gradient elution was used: $100 \%$ A to $80 \%$ A from 0 to $15 \mathrm{~min}$, then $80 \%$ A from 15 to $30 \mathrm{~min}$, and $80 \%$ A to $100 \%$ B from 30 to $33 \mathrm{~min}$, and finally $100 \% \mathrm{~B}$ from 33 to $36 \mathrm{~min}$, with $\mathrm{A}$, water/acetonitrile/formic acid $(90 / 10 / 1, \mathrm{v} / \mathrm{v} / \mathrm{v})$ and $\mathrm{B}$, water/ acetonitrile/formic acid (10/90/1, v/v/v).

All experiments were carried out using a quadrupole ion trap mass spectrometer (Finnigan LCQ, Thermo Finnigan) equipped with an electrospray ionization source operating in the positive ion mode. The electrospray needle was set at 4.4 $\mathrm{kV}$. The heated capillary was maintained at $220^{\circ} \mathrm{C}$. The capillary voltage and the tube lens offset were 3 and $-10 \mathrm{~V}$, respectively.

$\mathrm{MS}^{\mathrm{n}}$ experiments were performed on both $\mathrm{m} / \mathrm{z} 322$ and $\mathrm{m} / \mathrm{z} 328$ ions corresponding to the protonated $[\mathrm{M}+\mathrm{H}]^{+}$ions of DHN-MA and its deuterated analogue, respectively. A CRM (consecutive reaction monitoring) scan with three stages of mass analysis was used producing $\mathrm{MS}^{3}$ mass spectra from which the $m / z 164$ and $m / z 169$ fragment ions corresponding to the target and deuterated compounds, respectively, were extracted for integration and quantification. Helium buffer gas also served as collision gas for these

\section{(a) DHN-MA synthesis}

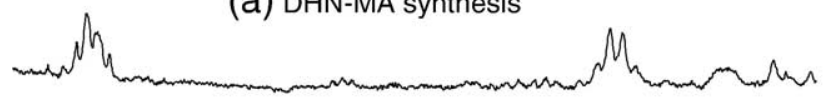

(b) DHN-MA purified from rat urine

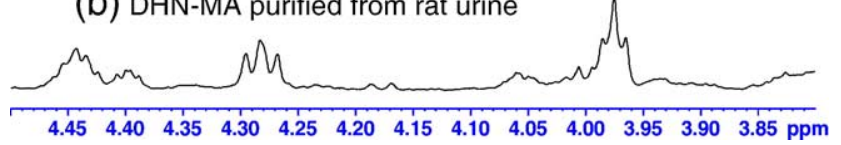

Fig. 1. $600 \mathrm{MHz}{ }^{1} \mathrm{H}$ NMR spectra $(\delta 4.5-3.8 \mathrm{ppm})$ in $\mathrm{CD}_{3} \mathrm{OD}$ of synthesized DHN-MA (a) and DHN-MA isolated from urine (b). 




Fig. 2. Standard curves obtained with EIA using the antiserum prepared from rabbit 1451. Standard curves with (4R)-DHN-MA (ם) and (4S)-DHN-MA ( $\square$ ).

experiments. All mass spectra were acquired using AGC (Automatic Gain Control). All results were expressed on the basis of a 24-h excretion.


Fig. 3. HPLC fractionation and immunochromatogram of rat urine with antiserum obtained from rabbit 1451. HPLC was carried out, after a C18 cartridge extraction step, as described under the Materials and methods except that the mobile phase was modified in order to achieve extensive separation of the different HNE urinary metabolites. The HPLC profile was obtained in a rat treated with radiolabeled HNE. The mobile phases consisted of ammonium acetate $20 \mathrm{mM}$ adjusted to $\mathrm{pH} 3.5$ (acetic acid) and acetonitrile 95:5 (v/v) in eluent $\mathrm{A}$ and 30:70 (v/v) in eluent B, respectively. Solvents were delivered as follows, $0-3 \mathrm{~min} 100 \% \mathrm{~A} ; 3-15 \mathrm{~min}$ linear gradient from 100 to $72 \% \mathrm{~A} ; 15-$ $30 \mathrm{~min} 72 \% \mathrm{~A} ; 30-35 \mathrm{~min}$ linear gradient from $72 \%$ A to $100 \% \mathrm{~B} ; 35-40 \mathrm{~min}$ $100 \% \mathrm{~B}$ and $40-60 \mathrm{~min} 100 \%$ acetonitrile. The first group of peaks (1) are polar metabolites of HNE, peak 2 is HNA-MA, peak 3 is DHN-MA together with HNE-MA (4), and peak 5 is HNA-lactone-MA. Urine used for the immunochromatogram was pooled urine from different rats. This pooled urine was fractionated by the HPLC system described above ( 4 fractions/min) and each fraction was tested for immunoreactivity.

\section{NMR analysis of urinary DHN-MA}

${ }^{1} \mathrm{H}$ NMR spectra were obtained at $300 \mathrm{~K}$ on a Bruker Avance DRX-600 spectrometer (Bruker, Wissembourg, France) operating at $600.13 \mathrm{MHz}$ and equipped with a $5 \mathrm{~mm}$ $\mathrm{H}, \mathrm{C}, \mathrm{N}$ inverse triple resonance TXI cryoprobe attached to a Cryoplatform (the preamplifier cooling unit).

Samples were dissolved in $600 \mu \mathrm{l}$ of deuterated methanol $\left(\mathrm{CD}_{3} \mathrm{OD}\right)$. One-dimensional ${ }^{1} \mathrm{H}$ NMR spectra were acquired using a standard pulse sequence for ${ }^{1} \mathrm{H}$ NMR. Ten thousand free induction decays (FIDs) were collected with a spectral width of $12 \mathrm{ppm}$ into $64 \mathrm{~K}$ data points. An exponential function equivalent to a line broadening of $0.3 \mathrm{~Hz}$ was applied prior to Fourier transformation.

\section{Statistics}

Regression and correlation studies were done using S-plus software (Insightful France, Toulouse, France).

\section{Results}

\section{NMR analysis of urinary DHN-MA}

DHN-MA isolated from urine and chemically synthesized DHN-MA from (4R)-HNE were analyzed by ${ }^{1} \mathrm{H}$ NMR. The ${ }^{1} \mathrm{H}$ NMR spectrum of synthesized DHN-MA showed, among other peaks, a multiplet at $4.44 \mathrm{ppm}$ corresponding to $\mathrm{CH}-\mathrm{COOH}$, and a triplet at $3.98 \mathrm{ppm}$ corresponding to $\mathrm{CH}_{2}-\mathrm{OH}$. For the DHN-MA originating from urine, an additional multiplet at $4.40 \mathrm{ppm}$, and an additional triplet at $4.28 \mathrm{ppm}$ were observed (Fig. 1). As the analysis by mass spectrometry of DHN-MA synthesized from racemic HNE showed the presence of two compounds with the same molecular weight and similar fragmentations, we can assume that these two isomers are diastereoisomers.

The synthesis of standard DHN-MA was obtained specifically from $(4 R)$-HNE. This explains why there was only one

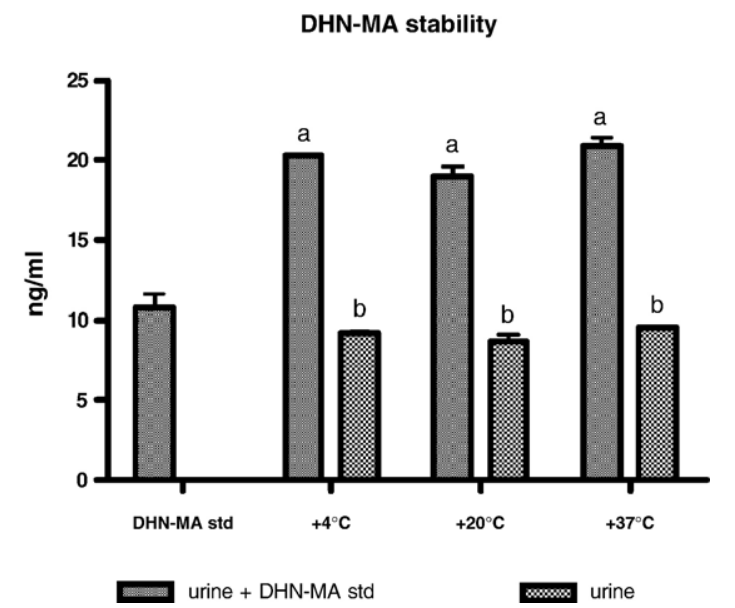

Fig. 4. DHN-MA stability under various conditions of temperature for $24 \mathrm{~h}$. Urine was rat urine without BHT. DHN-MA std: DHN-MA standard. a is significantly different from $b$. 
Table 1

Structures and estimated cross-reactivity (CR) of different compounds in the EIA system using antiserum 1451

\begin{tabular}{|c|c|c|}
\hline Structure & Compound & $\begin{array}{l}\mathrm{CR}(\%) \text { in EIA } \\
\text { using } 1451 \text { antiserun }\end{array}$ \\
\hline & DHN-MA(racemic) & - \\
\hline & $\operatorname{MA}(N$-acetyl-cysteine $)$ & $<0.1$ \\
\hline & 3-methylindole-MA & $<0.1$ \\
\hline & 4-HNE hemiacetal-MA & $<0.1$ \\
\hline & HNA-lactone-MA & $<0.1$ \\
\hline & HNA-MA & 30 \\
\hline & butan-1-ol-MA & $<0.1$ \\
\hline & 1-hexanol-MA & $<0.1$ \\
\hline & 1-nonanol-MA & $<0.1$ \\
\hline & DHN & $<0.1$ \\
\hline & HNA & 7 \\
\hline & 1,4-dihydroxyoctane MA & $<0.1$ \\
\hline
\end{tabular}

Table 1 (continued)

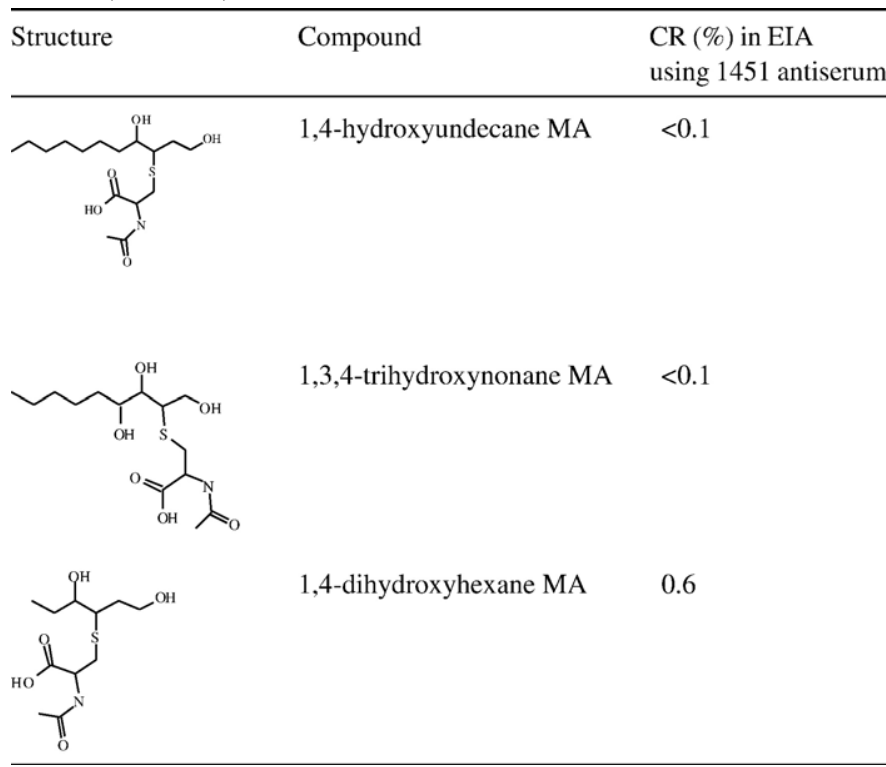

stereoisomer in the DHN-MA synthesized. The signals at 4.44 and $3.98 \mathrm{ppm}$ belonged to the $(4 R)$ stereoisomer and the signals at 4.40 and $4.28 \mathrm{ppm}$ belonged to the $(4 S)$ stereoisomer. The signals originating from the $(4 R)$ stereoisomer were quantitatively three times more intense than those from the other isomer found in rat urine.

\section{Binding parameters}

Rabbit polyclonal anti-DHN-MA antibodies were analyzed using DHN-MA-AChE enzyme tracer. The three immunized rabbits exhibited strong anti-DHN-MA immune response as revealed by polyclonal antibody titers $>1 / 20,000$ using EIA. However two rabbits (No. 1451 and No. 1453) showed a better sensitivity $\left(50 \% B / B_{0}<0.3 \mathrm{ng} / \mathrm{ml}\right)$ using a racemic mixture of $(4 R)$ - and $(4 S)$-DHN-MA while the third immunized rabbit proved to be at least 10 times less sensitive. The two selected antisera were further evaluated by using the individualized isomeric forms of DHN-MA as standard. As shown in Fig. 2, antiserum 1451 presents a better recognition (close to 50 times better with regard to the $50 \% \mathrm{~B} / B_{0}$ ) for the (4R)-than for the $(4 S)$-enantiomeric form of DHN-MA. Conversely, a better sensitivity was obtained for the (4S)-derivative using the 1453 antiserum (data not shown).

HPLC fractionation of control urine samples followed by EIA analysis was performed using both antisera. Interestingly a single immunoreactive peak (presenting minor shoulders) was detected using antiserum 1451 corresponding to the retention time of true DHN-MA (Fig. 3). The same experiment performed with antiserum 1453 showed widespread immunoreactivity all along the chromatogram, demonstrating a limited specificity.

These different results led us to select polyclonal antiserum 1451 for further determination of DHN-MA in whole urine. The optimized assay proved to be both sensitive, with a limit of quantification close to $0.02 \mathrm{ng} / \mathrm{ml}$, and accurate with an 
Table 2

Urinary DHN-MA excretion before and after treatment with $\mathrm{BrCCL}_{3}$ or TNBS

\begin{tabular}{llcc}
\hline $\begin{array}{l}\text { DHN-MA } \\
(\mathrm{ng} / 24 \mathrm{~h})\end{array}$ & $\begin{array}{l}\text { Before } \\
\text { treatment }\end{array}$ & $\begin{array}{l}24 \mathrm{~h} \text { after } \\
\text { treatment }\end{array}$ & $\begin{array}{l}48 \mathrm{~h} \text { after } \\
\text { treatment }\end{array}$ \\
\hline $\operatorname{BrCCl3}(n=5)$ & $45 \pm 12$ & $140 \pm 45^{*}$ & $229 \pm 7 * *$ \\
$\operatorname{TNBS}(n=10)$ & $40 \pm 11$ & $36 \pm 10$ & $30 \pm 12$ \\
\hline
\end{tabular}

Results are expressed as mean \pm SD.

* Is significantly different from pretreatment period value $(p<0.05)$ and ** is very significantly different from pretreatment value $(p<0.001)$. " $n$ " is the number of animals in each group.

intraassay coefficient of variation close to $5.7 \%(n=10)$, while the limit of quantification and the intraassay coefficient of variation for the previously used LC/MS method were 5 $\mathrm{ng} / \mathrm{ml}$ and $6.4 \%$, respectively. In order to verify the linearity of the EIA method, we added three different amounts of DHN-MA standard to rat urine. We plotted the analyzed samples (in duplicate) $(Y)$ against the added amounts (from 0.03 to $2.95 \mathrm{ng} / \mathrm{ml})(X)$ and we obtained the following linear regression: $Y=0.98 X+2.09$, with $r^{2}=0.99$ and where 2.09 $\mathrm{ng} / \mathrm{ml}$ is the amount of DHN-MA in urine before spiking with DHN-MA standard. The stability of DHN-MA in BHT untreated urine at room temperature and at $37^{\circ} \mathrm{C}$ was also checked. No modification of the signal was detected after a 24-h incubation at room temperature or at $37^{\circ} \mathrm{C}$ (Fig. 4).

\section{Cross-reactivity}

The specificity of the polyclonal anti-DHN-MA antibodies from antiserum 1451 was further analyzed by testing the recognition of various DHN-MA-related derivatives (see Materials and methods). Different mercapturic acids were used, namely $N$-acetylcysteine (mercapturic acid) and the mercapturic acid conjugates of 2-hexenal, 2-nonenal, crotonaldehyde, 1,4-dihydroxyhexene, 1,4-dihydroxyoctene, 1,4dihydroxyundecene, 4-hydroxynonenal, 4-hydroxynonenoic acid and its lactone form, 1,3,4-trihydroxynonene, and 3methylindole. HNA and DHN were also evaluated. Results are shown in Table 1.

Most of the compounds tested, including DHN and HNA, were not detected by the DHN-MA EIA, inducing no competition for tracer binding even at high concentrations $(>100 \mathrm{ng} / \mathrm{ml})$. Two products, i.e., HNA-MA and 1,4-dihy-



Fig. 5. Comparison of DHN-MA excretion in urine samples measured by LC/ MS and EIA. Representation of the regression analysis.

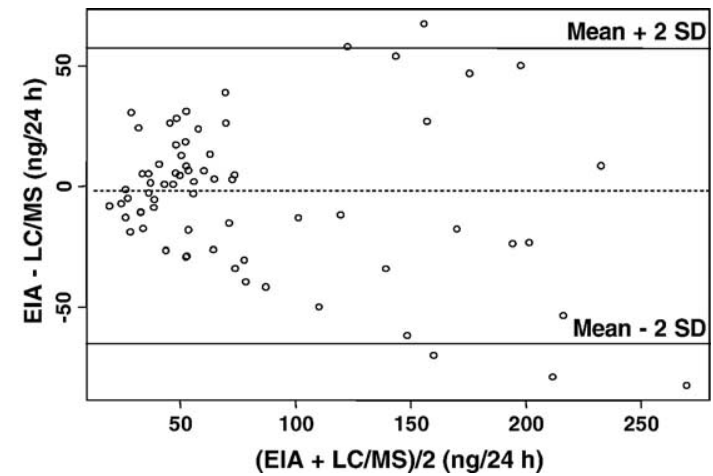

Fig. 6. Comparison of DHN-MA excretion in urine samples measured by LC/ MS and EIA using the Bland-Altman representation.

droxyoctane mercapturic acid, were recognized by the antibodies, exhibiting 30 and $7 \%$ cross-reactivity, respectively. Finally, a very faint competition also occurred with 1,4dihydroxyhexane mercapturic acid. These experiments allowed better evaluation of the structural moieties required to obtain correct antibody binding.

\section{Validation of the method}

A further validation of the EIA method was achieved by comparing results obtained on different rat urine $(n=67)$ by EIA and by LC/MS, which is an independent analytical method used to estimate DHN-MA, described and validated in a previous study [25]. The different urine samples came from rats with different oxidative status. Table 2 shows that a treatment with $\mathrm{BrCCl}_{3}$ increased significantly the excretion of DHN-MA, while TNBS intracolonic instillation had no significant effect.

A good correlation, i.e., statistically highly significant, was obtained between the two methods EIA $=0.79 \times$ LC/MS + 14.03; $R=0.877, p<10^{-8}$ (Fig. 5).

When data were analyzed by the Bland and Altman graphical technique [26] (Fig. 6) that plots the mean of and the difference between the two values obtained with EIA and LC/MS, respectively, no correlation was observed between these two parameters. This indicates that there is no relationship between the measurement of error and the true value.

\section{Discussion}

HNE formation is enhanced under conditions of oxidative stress/lipid peroxidation [4]. However, its chemical reactivity is a serious drawback for its use as a valuable biomarker of these oxidative processes except for the measurement of HNE/ protein adducts which are believed to be responsible for HNE biological activity. Moreover, this compound is not present in urine and, hence, cannot be related to an index of oxidative stress representative of oxidative events occurring in the whole body over a relatively long period of time (up to $24 \mathrm{~h}$ ). But such an index would be useful for monitoring the evolution of chronic pathologies.

DHN-MA is the major urinary metabolite of HNE in the rat when this compound is administered intravenously [22]. This 
end-product of HNE metabolism is a very stable compound that does not exhibit the same drawbacks as its precursor. It has also been found in rat and human urine at a basal level [13]. Its excretion in the rat, measured by LC/MS after tedious purification procedures as described in the present paper, is increased under conditions of chemically induced oxidative stress [14]. Consequently, DHN-MA appears to be a good candidate as a biomarker of lipid peroxidation. The measurement of DHN-MA can be useful as a complement to immunohistochemistry detection of HNE/protein adducts and in this case, HNE would be a major bioactive marker through the measurement of its derivatives.

Immunological methods have been used by other authors to measure mercapturic acids in human urine or to measure HNE/ protein adducts $[11,12,27]$. In the present study we present for the first time an immunological method for measuring DHNMA that would allow very specific and rapid quantification with a high sample throughput, which is an improvement, compared to the LC/MS method we have already developed [25].

Among the three antisera produced in order to develop this EIA, only two were sensitive enough to be further characterized. However, these antisera showed significant enantioselectivity. Antiserum 1453 is more specific of DHN-MA synthesized from $(4 S)$-HNE. Validation was then further performed with antiserum 1451 which is more specific of DHN-MA synthesized from (4R)-HNE. In fact, different studies were performed to clarify the respective excretion of the different DHN-MA isomers. We have previously shown that HNE metabolism was enantioselective and that rats treated with $(4 R)$-HNE excreted three times more DHN-MA than those treated with $(4 S)$-HNE [28]. Since HNE is produced in vivo as a racemic mixture [29], most of the excreted DHN-MA must derive from $(4 R)$-HNE. In the present study, we showed that the predominant isomer obtained after NMR analysis of urinary DHN-MA corresponded to the one obtained chemically from $(4 R)$-HNE. This justifies the choice of antiserum 1451 instead of antiserum 1453 to quantify urinary DHN-MA. We improved the measurement by using DHN-MA synthesized from (4R)HNE as standard. All further validation and cross-reactivity studies were performed using this system.

Cross-reactivity studies showed that the length of the hydrocarbon chain was important since the cross-reactivity appeared to be directly related to this factor (DHN-MA > 1,4dihydroxyoctane-MA > 1,4-dihydroxyhexane-MA). Obviously the absence of the mercapturic acid moiety totally abolished the recognition, as well as the hydroxyl function on C-4, while the function located on the C-1, even if important, is not crucial, since the carboxylic acid of HNA-MA only induced a 3 -fold decrease in EIA sensitivity. The latter compound was shown to be an end-product of HNE when the metabolism of HNE was investigated in the rat [22], so it is likely to be found in urine. However, one can assume that the only source of HNA-MA is HNE as is the case for DHN-MA, so the measurement of this compound, with a cross-reactivity of $30 \%$, should also reflect the production of HNE. Due to this cross-reactivity with HNA-MA, the measurement of DHNMA with EIA should be overestimated compared to measurement with LC/MS. The fact that the contrary was observed can be explained by the underestimation of DHN-MA originating from $(4 S)$-HNE, which is not counterbalanced by the reactivity with HNA-MA.

Indeed, the aim of this study was to validate our new EIA method against a spectroscopic quantification method for the determination of DHN-MA in rat urine. The validation of the EIA method against LC/MS exhibited a good correlation. These results were further analyzed by the Bland-Altman plot, i.e., a classical statistical method, which is widely used to simply compare the two measurement techniques. In the graphical method, the differences between the two techniques are plotted against the averages of values given by the two techniques; this is a useful way to reveal a relationship between the differences and the averages, and to look for a systematic bias and the nonuniformity of error [30], which could not be revealed with the regression analysis. For example, the determination of a regression line with a slope different from 0 (or a curvature) when analyzing the BlandAltman plot would indicate the existence of a bias. Indeed, this graphical analysis of bias between the two techniques is very similar to the more general analysis of residuals used in statistical procedures such as analysis of variance or linear regression. However, the Bland-Altman plot does not give an idea of the accuracy of the methods.

Nevertheless, high standard deviations were observed between the two sets of experimental data. This can be explained by inaccurate measurement, probably due to the two necessary cleaning procedures (SPE cartridge and HPLC purification) before mass spectrometry analysis and to the interfering factors which can compete with DHN-MA for the signal acquisition in the urine matrix [25]. Moreover, it should also be noted that the ion trap analyzer is not the ideal tool for mass spectrometric quantitative determinations.

We showed here that $\mathrm{BrCCl}_{3}$, which is a classical inducer of lipid peroxidation, induced a five-time increase in DHNMA urinary excretion in rat. On the contrary, acute colon inflammation induced by TNBS failed to increase DHN-MA urinary excretion. Different explanations can be invoked, such as the loss of HNE in inflamed/necrotic cell desquamation in feces or a modification of HNE biotransformations due to TNBS. Nevertheless, thanks to the development of this convenient DHN-MA measurement, we will now be able to test this compound as a biomarker of lipid peroxidation under a range of different pathological conditions.

\section{Acknowledgments}

We thank Dr. Daniella Zanetti (University of Turin, Italy) and Prof. Hank Segall (University of California, Davis, CA) for their generous gift of standard molecules for the crossreactivity studies. We thank Jean-Pierre Cravedi and Alain Paris (INRA, Toulouse) for helpful discussions. We thank Raymond Gazel and Florence Blas-y-Estrada (INRA, Tou- 
louse) for taking good care of the animals. This study was supported by a grant from INRA (AIP P00231).

\section{References}

[1] Kehrer, J. P.; Smith, C. V. Free radicals in biology: sources, reactivities, and roles in the etiology of human diseases. In: Balz Frei, Ed., Natural antioxidants in human health and disease. San Diego, CA: Academic Press; 1994: 25-55.

[2] Roberts, L. J.; Morrow, J. D. Measurement of F(2)-isoprostanes as an index of oxidative stress in vivo. Free Radic. Biol. Med. 28:505-513; 2000.

[3] Springfield, J. R.; Levitt, M. D. Pitfalls in the use of breath pentane measurements to assess lipid peroxidation. J. Lipid Res. 35:1497-1504; 1994.

[4] Esterbauer, H.; Schaur, R. J.; Zollner, H. Chemistry and biochemistry of 4-hydroxynonenal, malonaldehyde and related aldehydes. Free Radic. Biol. Med. 11:81-128; 1991.

[5] Janero, D. R. Malondialdehyde and thiobarbituric acid-reactivity as diagnostic indices of lipid peroxidation and peroxidative tissue injury. Free Radic. Biol. Med. 9:515-540; 1990.

[6] Zarkovic, N. 4-Hydroxynonenal as a bioactive marker of pathophysiological processes. Mol. Aspects Med. 24:281-291; 2003.

[7] Dianzani, M. U. 4-Hydroxynonenal and cell signalling. Free Radic. Res. 28:553-560; 1998.

[8] Parola, M.; Bellomo, G.; Robino, G.; Barrera, G.; Dianzani, M. U. 4Hydroxynonenal as a biological signal: molecular basis and pathophysiological implications. Antioxid. Redox. Signal. 1:255-284; 1999.

[9] Poli, G.; Schaur, R. J. 4-Hydroxynonenal in the pathomechanisms of oxidative stress. IUBMB Life 50:315-321; 2000.

[10] Zarkovic, N.; Zarkovic, K.; Schaur, R. J.; Stolc, S.; Schlag, G.; Redl, H.; Waeg, G.; Borovic, S.; Loncaric, I.; Juric, G.; Hlavka, V. 4-Hydroxynonenal as a second messenger of free radicals and growth modifying factor. Life Sci. 65:1901-1904; 1999.

[11] Uchida, K.; Szweda, L. I.; Chae, H. Z.; Stadtman, E. R. Immunochemical detection of 4-hydroxynonenal protein adducts in oxidized hepatocytes. Proc. Natl Acad. Sci. USA 90:8742-8746; 1993.

[12] Waeg, G.; Dimsity, G.; Esterbauer, H. Monoclonal antibodies for detection of 4-hydroxynonenal modified proteins. Free Radic. Res. 25:149-159; 1996.

[13] Alary, J.; Debrauwer, L.; Fernandez, Y.; Cravedi, J. P.; Rao, D.; Bories, G. 1,4-Dihydroxynonene mercapturic acid, the major end metabolite of exogenous 4-hydroxy-2-nonenal, is a physiological component of rat and human urine. Chem. Res. Toxicol. 11:130-135; 1998.

[14] Peiro, G.; Alary, J.; Cravedi, J.P.; Rathahao, E.; Steghens, J.P.; Guéraud, F. 1,4-Dihydroxynonene mercapturic acid, an urinary metabolite of 4hydroxynonenal, as a biomarker of lipid peroxidation. Biofactors In press.

[15] Esterbauer, H.; Weger, W. Uber die wirkungen von aldehyden auf gesunde und maligne zellen, 3: mitt: Synthese von homologen 4hydroxy-2-alkenalen, II. Monatsch. Chem. 98:1994-2000; 1967.
[16] Bravais, F.; Rao, D.; Alary, J.; Rao, R. C.; Debrauwer, L.; Bories, G. Synthesis of 4-Hydroxy[4-H-3]-2(E)-Nonen-1-Al-Diethylacetal. J. Labelled Compd. Rad. 36:471-477; 1995.

[17] Caruelle, D.; Grassi, J.; Courty, J.; Groux-Muscatelli, B.; Pradelles, P.; Barritault, D.; Caruelle, J. P. Development and testing of radio and enzyme immunoassays for acidic fibroblast growth factor (aFGF). Anal. Biochem. 173:328-339; 1988.

[18] Pradelles, P.; Grassi, J.; Maclouf, J. Enzyme immunoassays of eicosanoids using acetylcholine esterase as label: an alternative to radioimmunoassay. Anal. Chem. 57:1170-1173; 1985.

[19] Wang, Z.; Ciabattoni, G.; Creminon, C.; Lawson, J.; Fitzgerald, G. A.; Patrono, C.; Maclouf, J. Immunological characterization of urinary 8epi-prostaglandin F2 alpha excretion in man. J. Pharmacol. Exp. Ther. 275:94-100; 1995.

[20] Ellman, G. L.; Courtney, K. D.; Andres, V., Jr.; Feather-Stone, R. M. A new and rapid colorimetric determination of acetylcholinesterase activity. Biochem. Pharmacol. 7:88-95; 1961.

[21] Abraham, G. E. Radioimmunoassay of steroids in biological fluids. Clin. Biochem. 7:193-201; 1974.

[22] Alary, J.; Bravais, F.; Cravedi, J. P.; Debrauwer, L.; Rao, D.; Bories, G. Mercapturic acid conjugates as urinary end metabolites of the lipid peroxidation product 4-hydroxy-2-nonenal in the rat. Chem. Res. Toxicol. 8:34-39; 1995.

[23] Chen, H. J.; Chung, F. L. Epoxidation of trans-4-hydroxy-2-nonenal by fatty acid hydroperoxides and hydrogen peroxide. Chem. Res. Toxicol. 9:306-312; 1996.

[24] Allevi, P.; Anastasia, M.; Cajone, F.; Ciuffreda, P.; Sanvito, A. M. Enzymatic resolution of (R)-(E)-4-Hydroxyalk-2-Enals and (S)-(E)-4Hydroxyalk-2-Enals Related to Lipid-Peroxidation. J. Org. Chem. 58: 5000-5002; 1993.

[25] Rathahao, E.; Peiro, G.; Alary, J.; Guéraud, F.; Debrauwer, L. Liquid chromatography-multistage tandem mass spectrometry for the quantification of dihydroxynonene mercapturic acid (DHN-MA), a urinary endmetabolite of 4-hydroxynonenal. Anal. Bioanal. Chem. 381:1532-1539; 2005.

[26] Bland, J. M.; Altman, D. G. Statistical methods for assessing agreement between two methods of clinical measurement. Lancet 1:307-310; 1986.

[27] Lohse, C.; Jaeger, L. L.; Staimer, N.; Sanborn, J. R.; Jones, A. D.; Lango, J.; Gee, S. J.; Hammock, B. D. Development of a class-selective enzyme-linked immunosorbent assay for mercapturic acids in human urine. J. Agric. Food Chem. 48:5523-5913; 2000.

[28] Guéraud, F.; Crouzet, F.; Alary, J.; Rao, D.; Debrauwer, L.; Laurent, F.; Cravedi, J.P. Enantioselective metabolism of (R)- and (S)-4-hydroxynonenal in rat. Biofactors In press.

[29] Bringmann, G.; Gassen, M.; Lardy, R. 4-Hydroxynon-2-Enal, a Cytotoxic Lipid-Peroxidation Product, and its C-5-Analog 4-Hydroxypent-2-Enal-Enantioselective Synthesis and Stereoanalysis. Tetrahedron 50:10245-10252; 1994.

[30] Dewitte, K.; Fierens, C.; Stockl, D.; Thienpont, L. M. Application of the Bland-Altman plot for interpretation of method-comparison studies: a critical investigation of its practice. Clin. Chem. 48:799-7801; author reply $801-802 ; 2002$. 